\title{
Interactive comment on "Airborne radionuclides and heavy metals in High Arctic terrestrial environment as the indicators of sources and transfers of contamination" by Edyta Łokas et al.
}

\section{Anonymous Referee \#2}

Received and published: 23 April 2019

Comment on "Airborne radionuclides and heavy metals in High Arctic terrestrial environment as the indicators of sources and transfers of contamination", E. Łokas et al.

Anonymous reviewer no. 2

General comments:

From an analytical perspective, this article represents a great amount of work with regard to sample collection and processing, chemical and radiochemical separations, instrumental measurements, and interpretation of results. A systematic organization of the measurement results is found in the extensive tables of analytical data; these will 
enable valuable comparisons with past and future data obtained by other researchers in that region. Perhaps referring to the tables, figures and plots with very brief descriptions should comprise the "Results" section. I'm not sure that it is necessary to mention the ranges of all the analytes in the text when this information can be seen in the tables.

The "Discussion" section is partitioned into three subsections. Subsection 4.2 "The source of radionuclides and heavy metals contamination" is essentially entirely devoted to radionuclides; perhaps it would be better just to drop the "heavy metals" part from this title since it is discussed in depth in subsection 4.3.

Some of the actual discussion of the results, especially for stable heavy metals and correlations among them (subsections 3.3 and 3.4), occurs in the "Results" section. It is recommended to integrate these remarks into the "Discussion" section along with the existing material.

Uncertainties are presented with the tables S2 through S5 giving radionuclide measurement results; however, I cannot find any mention in the text of whether these uncertainties are at the $68 \%(\mathrm{k}=1)$ or $95 \%(\mathrm{k}=2)$ confidence level. A general statement about the confidence level of uncertainties should be given early in the text (e.g., at the very beginning of the "Results" section). In addition, the main contributions to the radioanalytical uncertainties should be mentioned (e.g., counting statistics, calibrations, tracer concentrations, etc.).

Table S6 lists all of the stable element measurement results, but there are no uncertainties attached to these values. A statement of uncertainty "ranges" associated with each element concentration measurement should be given for the reader, perhaps at the column headings or as a footnote.

My recommendation is that this article should be published with minor revisions as outlined above.

Printer-friendly version

Specific comments

Discussion paper 
1. Although I believe Svalbard and Spitsbergen refer to the same archipelago, the authors should choose one or the other to be used consistently in the article.

2. In the abstract, it would be useful to mention that the Kaffioyra region is located in Spitsbergen/Svalbard.

3. In subsection 2.3.2 "Heavy metal analyses", it is not mentioned if separate subsamples (from those used for radionuclide analyses) were used for the stable element determinations. If separate samples were used, how much material and what dissolution method(s) was (were) used to prepare them for the flame atomic absorption and mass spectrometer measurements?

4. How was sample organic content assessed and related to LOI (which needs to be defined in the text)?

5. The plots of depth distribution in Fig. 2 are important but very difficult to read; a significant improvement in quality is needed.

6. The reference "Łokas et al., 2010" in line 10 on page 5 is missing from the "References" section at the end of the article. I suspect it is Nukleonika 2010, volume 55(2), pages 195 - 199, but please correct this oversight.

7. In line 6 on page 17, "average mass ratios" should be "average atom ratios" to be consistent with all of the previous text.

8. In line 8 on page 17, ". . . initial soils from other west cost of Spitsbergen" is confusing; perhaps the authors meant ". . . initial soils from the other (west) coast of Spitsbergen"?

9. In lines 8-9 on page 17, perhaps to write "We observed an excess of 238Pu in cryoconite samples similar to that which we observed in other initial soils in Spitsbergen, and this enrichment of $238 \mathrm{Pu}$ is derived from sources other than $239 \mathrm{Pu}$. This is due to pure 238Pu from a satellite re-entry ..." 
Interactive comment on The Cryosphere Discuss., https://doi.org/10.5194/tc-2019-34, 2019.

TCD

Interactive

comment

Printer-friendly version

Discussion paper 